\title{
Contrast sensitivity in diabetic subjects with and without retinopathy
}

\author{
I. M. GHAFOUR, ${ }^{1}$ W. S. FOUlds,${ }^{1}$ D. Allan ${ }^{2}$ ANd E. McCluRE ${ }^{1}$ \\ From the 'Tennent Institute of Ophthalmology, University of Glasgow, and the \\ ${ }^{2}$ West of Scotland Health Boards, Department of Clinical Physics and Bio-Engineering, Glasgow
}

SUMmary The clinical usefulness of the Arden grating test in assessing early abnormalities in retinal function of diabetics has been explored. Although the test revealed significant differences in constrast sensitivities between diabetics and normal persons, the large variances in the test scores of diabetics limit its use as a clinical tool for the screening of diabetic patients.

Diabetes is said to be associated with detectable alterations in colour perception before the development of ophthalmoscopically detectable retinopathy. ${ }^{1}$ The Arden grating test ${ }^{2}$ is claimed to detect disturbances of retinal integrative function even when acuity is normal. The test was used to assess whether it was of clinical value in detecting early abnormality in retinal function in diabetic subjects without retinopathy or in those with established retinopathy and whether it was useful in differentiating serious from not serious retinopathy.

\section{Materials and methods}

The test was carried out as described by Arden and Jacobson $^{2}$ except that standard artificial daylight was used (Verivide Cabinet, Leslie Hubble Ltd). Plates were presented at a standard distance of $57 \mathrm{~cm}$ and each eye was tested separately. The test was used in 80 normal subjects (age range 24 to 68 , mean age 46 , median age 45 years) and in 99 diabetic subjects (age range 27 to 70 , mean age 47 , median age 49 years). The ages of the 2 groups of subjects were comparable $(p>0 \cdot 5$, Mann-Whitney nonparametric test). Fortytwo of the diabetics had no detectable retinopathy on ophthalmoscopy. Twenty-two had background retinopathy, that is, scattered haemorrhages, microaneurysms, and a small number of hard exudates with retention of normal visual acuity. Twenty-nine patients had proliferative retinopathy as evidenced by disc or other new vessels. The visual acuities among

Correspondence to Professor W. S. Foulds, Tennent Institute of Ophthalmology, Western Infirmary, Glasgow G11 6NT. patients with proliferative retinopathy ranged from $6 / 5$ to $6 / 36$ with a mean level of $6 / 9$ and a median of $6 / 9$. For analysis only one eye (the right) was used from each patient tested.

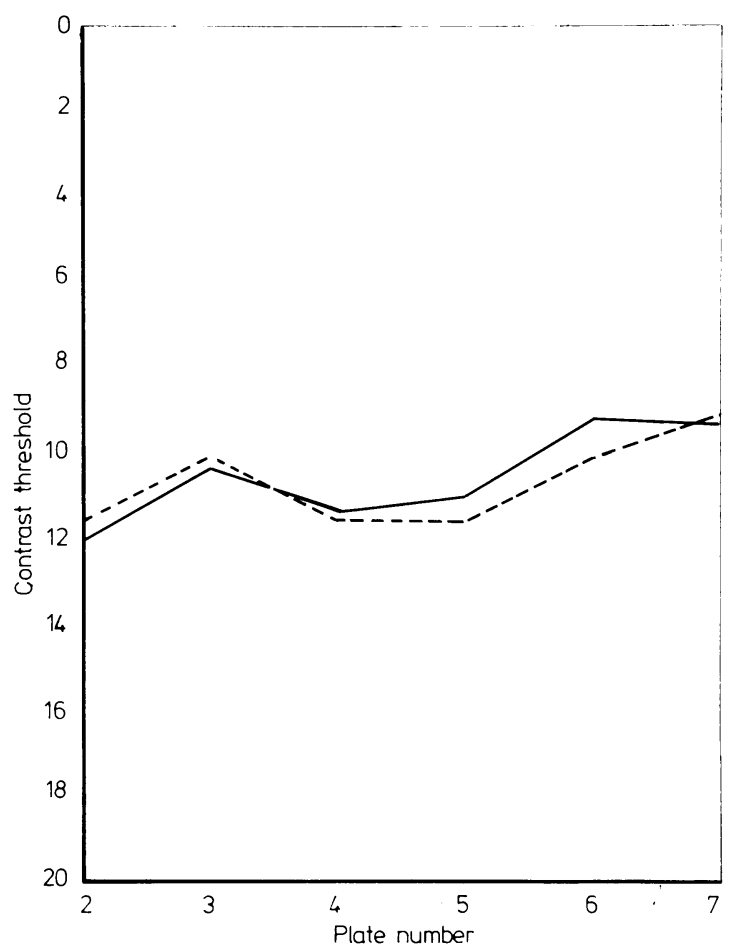

Fig. 1 Mean contrast thresholds on Arden grating test for normal persons. (___ Our controls. (_____) Arden and Jacobson normal persons. 
Table 1 A comparison of mean contrast thresholds for Arden and Jacobson's normals, our controls, all diabetics, and different groups of diabetic patients. Standard deviations are shown in brackets

\begin{tabular}{|c|c|c|c|c|c|c|}
\hline Plate & 2 & 3 & 4 & 5 & 6 & 7 \\
\hline Arden's figures $(\mathrm{SD}=2)$ & $11 \cdot 50$ & $10 \cdot 00$ & $11 \cdot 50$ & $11 \cdot 50$ & $10 \cdot 00$ & $9 \cdot 00$ \\
\hline Mean readings of our normal subjects & $\begin{array}{l}11 \cdot 96 \\
(2 \cdot 27)\end{array}$ & $\begin{array}{l}10 \cdot 26 \\
(1 \cdot 89)\end{array}$ & $\begin{array}{l}11 \cdot 33 \\
(2 \cdot 08)\end{array}$ & $\begin{array}{l}10 \cdot 90 \\
(1.98)\end{array}$ & $\begin{array}{c}9 \cdot 08 \\
(2 \cdot 25)\end{array}$ & $\begin{array}{c}9 \cdot 19 \\
(2 \cdot 56)\end{array}$ \\
\hline Mean reading of normal subjects & $\begin{array}{l}11 \cdot 96 \\
(2 \cdot 27)\end{array}$ & $\begin{array}{l}10 \cdot 26 \\
(1 \cdot 89)\end{array}$ & $\begin{array}{l}11 \cdot 33 \\
(2 \cdot 08)\end{array}$ & $\begin{array}{l}10 \cdot 90 \\
(1.98)\end{array}$ & $\begin{array}{c}9 \cdot 08 \\
(2 \cdot 25)\end{array}$ & $\begin{array}{c}9 \cdot 19 \\
(2 \cdot 56)\end{array}$ \\
\hline Mean reading of 99 diabetics & $\begin{array}{l}13 \cdot 42 \\
(3 \cdot 72)\end{array}$ & $\begin{array}{l}11 \cdot 17 \\
(3 \cdot 39)\end{array}$ & $\begin{array}{l}13 \cdot 37 \\
(3 \cdot 54)\end{array}$ & $\begin{array}{l}13 \cdot 73 \\
(3.99)\end{array}$ & $\begin{array}{l}13 \cdot 91 \\
(6 \cdot 39)\end{array}$ & $\begin{array}{l}15 \cdot 80 \\
(7 \cdot 31)\end{array}$ \\
\hline Normal & $\begin{array}{l}11 \cdot 96 \\
(2 \cdot 27)\end{array}$ & $\begin{array}{l}10 \cdot 26 \\
(1 \cdot 89)\end{array}$ & $\begin{array}{l}11 \cdot 33 \\
(2 \cdot 08)\end{array}$ & $\begin{array}{l}10 \cdot 90 \\
(1.98)\end{array}$ & $\begin{array}{c}9 \cdot 08 \\
(2 \cdot 25)\end{array}$ & $\begin{array}{c}9 \cdot 19 \\
(2 \cdot 56)\end{array}$ \\
\hline 'No retinopathy' diabetic group & $\begin{array}{l}12 \cdot 86 \\
(4 \cdot 03)\end{array}$ & $\begin{array}{c}9.53 \\
(2.99)\end{array}$ & $\begin{array}{l}11 \cdot 73 \\
(3 \cdot 32)\end{array}$ & $\begin{array}{l}11 \cdot 60 \\
(3 \cdot 50)\end{array}$ & $\begin{array}{l}12 \cdot 40 \\
(7 \cdot 28)\end{array}$ & $\begin{array}{l}13 \cdot 26 \\
(8 \cdot 07)\end{array}$ \\
\hline Normal controls & $\begin{array}{l}11 \cdot 96 \\
(2 \cdot 27)\end{array}$ & $\begin{array}{l}10 \cdot 26 \\
(1 \cdot 89)\end{array}$ & $\begin{array}{l}11 \cdot 33 \\
(2 \cdot 08)\end{array}$ & $\begin{array}{l}10 \cdot 90 \\
(1 \cdot 98)\end{array}$ & $\begin{array}{c}9 \cdot 08 \\
(2 \cdot 25)\end{array}$ & $\begin{array}{c}9 \cdot 19 \\
(2 \cdot 56)\end{array}$ \\
\hline 'Background' retinopathy group & $\begin{array}{l}13 \cdot 60 \\
(2 \cdot 87)\end{array}$ & $\begin{array}{l}12 \cdot 00 \\
(2 \cdot 23)\end{array}$ & $\begin{array}{l}13 \cdot 33 \\
(3 \cdot 06)\end{array}$ & $\begin{array}{l}13 \cdot 13 \\
(2 \cdot 64)\end{array}$ & $\begin{array}{l}12 \cdot 66 \\
(4 \cdot 33)\end{array}$ & $\begin{array}{l}14 \cdot 86 \\
(5 \cdot 20)\end{array}$ \\
\hline 'Proliferative' retinopathy group & $\begin{array}{l}13 \cdot 80 \\
(4 \cdot 31)\end{array}$ & $\begin{array}{l}12 \cdot 00 \\
(4 \cdot 22)\end{array}$ & $\begin{array}{l}15 \cdot 06 \\
(3 \cdot 65)\end{array}$ & $\begin{array}{l}16 \cdot 46 \\
(4 \cdot 18)\end{array}$ & $\begin{array}{l}16 \cdot 66 \\
(6 \cdot 65)\end{array}$ & $\begin{array}{l}19 \cdot 26 \\
(7 \cdot 43)\end{array}$ \\
\hline
\end{tabular}

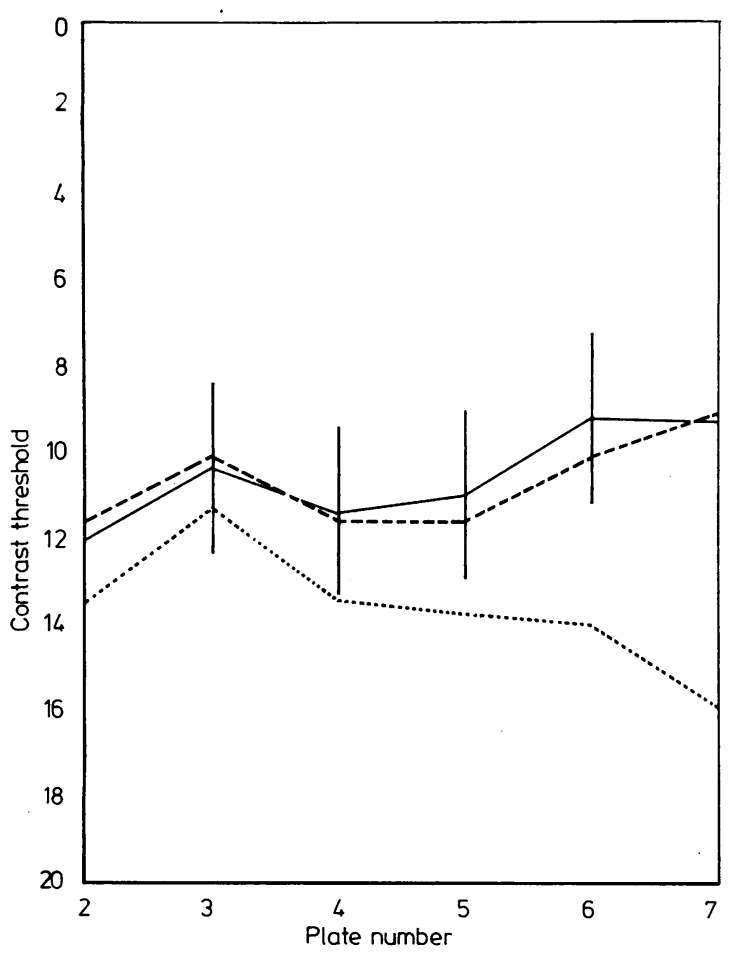

Fig. 2 Mean contrast thresholds for: (__ Our normals. (_._._-) Arden and Jacobson's normals. (.....) All diabetics. The vertical bars mark \pm 2 SD limits for our normals.

\section{Results}

The mean contrast thresholds for normal and diabetic subjects for each of the 6 plates of differing spatial frequency used are shown in Table 1 together with the relevant standard deviations, as also are the mean normal values quoted by Arden and Jacobson. ${ }^{2}$

In general, for normal subjects our results for each plate were in agreement with those of Arden and Jacobson (Fig. 1) except for plates 5 and 6 , where a significantly lower threshold was found for our normal subjects $(\mathrm{p}<0 \cdot 001$, each plate).

When the results for the 99 diabetic patients were compared with our normal results (or with those published by Arden and Jacobson), a significantly higher mean threshold was found for each plate (Fig. 2). When the results for our normal controls (Fig. 3) were compared with those from diabetic subjects without retinopathy, a significant increase in the threshold was found for the higher frequency plates 6 and 7 (whereas with Arden's control values a significant difference was also found with the low frequency plate number 2 ).

As would be expected, the results from our normal controls differed significantly from those obtained from patients with either background retinopathy or proliferative retinopathy (Fig. 4), as did the same results when Arden's control data were used.

When the various grades of retinopathy within the diabetic group were compared, the results were less clear-cut, though significant differences were found. 


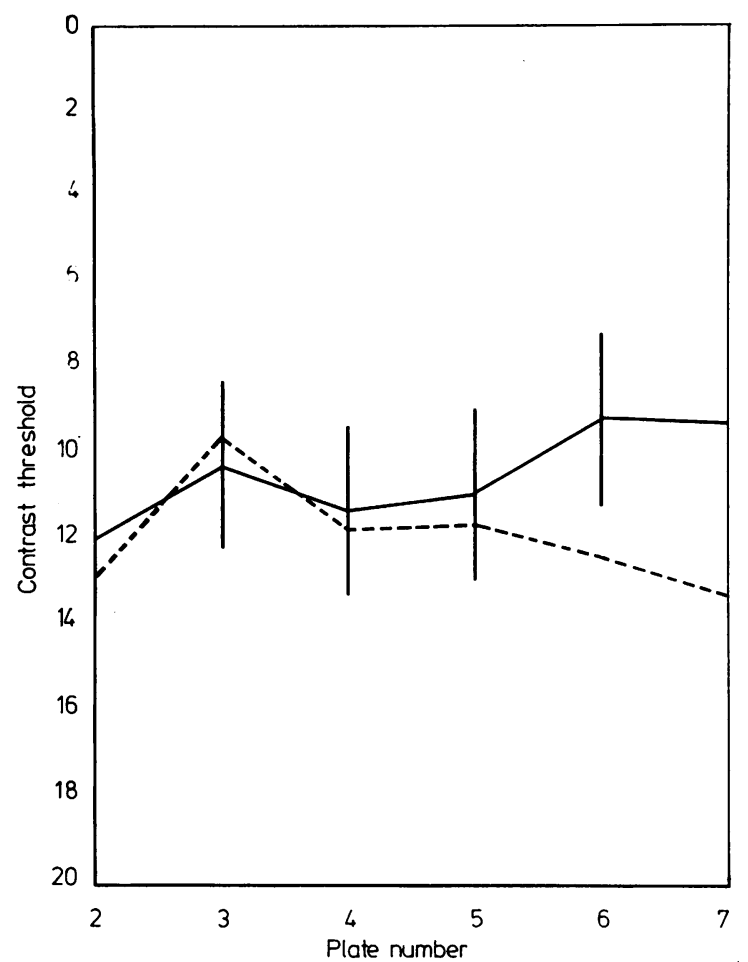

Fig. 3 Mean contrast thresholds for: (__ Our normals. (__-_- ) 'No retinopathy' group. $\pm 2 S D$ limits for the normals are shown.

Thus the results for patients with diabetes but without retinopathy were significantly different in plates 3,4 , and 5 from those with background retinopathy and in all plates except plate 2 when compared with results from patients with proliferative retinopathy. Even when background retinopathy was compared with proliferative retinopathy, this latter group showed significantly increased thresholds for plates 5,6 , and 7 as compared with the former group. The results of the above comparisons are summarised in Fig. 5. The comparisons were made by a modified $t$ test, applicable to cases with unequal variances.

It is worth noting that unlike the control group, in which the variance for each plate was similar $(\mathrm{SD}=$ 1.89 to 2.56 ), in all the diabetic groups the variances tended to be greater than in the controls, and particularly when higher frequency plates were used. An F test was used to assess whether the increased variance was significant, and significant values are marked with an asterisk in Fig. 6.

\section{Discussion}

Our results with the Arden grating test in normal

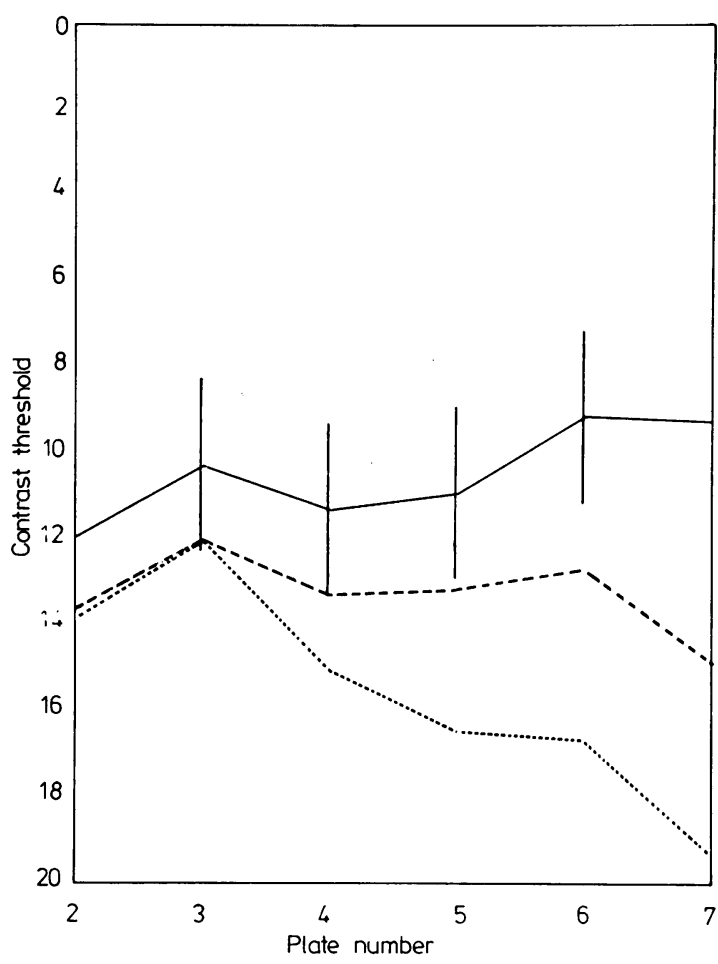

Fig. 4 Mean contrast thresholds for: (__ Our normals. (______ 'Background' retinopathy group. (......) 'Proliferative' retinopathy group. $\pm 2 S D$ limits for normals are shown.

subjects show a lower threshold for plates 5 and $6(1 \cdot 6$ cycles/degree and 3.2 cycles/degree respectively) than those previously published by Arden and Jacobson $^{2}$ but are in agreement with figures recently published by Singh et al. ${ }^{3}$ The results of the Arden grating test are to some degree age-related, ${ }^{4}$ and the difference may reflect a different age composition in Arden and Jacobson's material and our own.

It is of interest that diabetic patients without retinopathy show increased thresholds at the higher spatial frequencies tested, which suggests that the functional deficit for these frequencies may precede ophthalmoscopically visible retinopathy.

Even within the group of diabetic patients increasing severity of retinopathy (background versus proliferative) was, as might be expected, associated with a decreased contrast sensitivity to grating patterns and an increasing variability in results, especially for plates of high frequency content.

Unfortunately the relatively large standard deviations in the groups affected by retinopathy resulted in considerable overlap between groups, so that the test was not found to be clinically useful in separating individual diabetic patients into serious or not serious 


\begin{tabular}{|c|c|c|c|c|c|c|c|}
\hline Place & 2 & 3 & 4 & 5 & 6 & 7 & Comparison \\
\hline & & & & * & * & & $\begin{array}{l}\text { Nornal Controls V. } \\
\text { Arden Mormels }\end{array}$ \\
\hline & * & * & * & * & * & * & $\begin{array}{l}\text { Arden Wormels v. } \\
\text { All Diabetice }\end{array}$ \\
\hline & * & & & & * & $*$ & 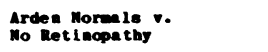 \\
\hline & * & * & * & * & $*$ & $*$ & $\begin{array}{l}\text { Arden Morm } 18 \text { O. } \\
\text { Beckercound Retinope thy }\end{array}$ \\
\hline & * & * & * & * & * & $*$ & $\begin{array}{l}\text { Arden Wormals V. } \\
\text { Proli ferative Retimopating }\end{array}$ \\
\hline & * & * & $*$ & $*$ & * & * & $\begin{array}{l}\text { Mormal Controls V. } \\
\text { All Diebetics }\end{array}$ \\
\hline & & & & & * & * & $\begin{array}{l}\text { Mormal Controls M. } \\
\text { Wo netinope thy }\end{array}$ \\
\hline & $*$ & * & * & * & * & $*$ & $\begin{array}{l}\text { Mornel Controls r. } \\
\text { Beckeround Retinoppethy }\end{array}$ \\
\hline & * & $*$ & * & * & * & * & $\begin{array}{l}\text { Mornal Controls } \\
\text { Proll ferative Ret inopa thy }\end{array}$ \\
\hline & & * & * & * & & & $\begin{array}{l}\text { No Retinopathy } \\
\text { Backerround Retinopathy }\end{array}$ \\
\hline & & $*$ & * & * & * & * & $\begin{array}{l}\text { Mo Ret inopathy N- } \\
\text { Proll ferative Ret inopathy }\end{array}$ \\
\hline & & & & * & $*$ & * & $\begin{array}{l}\text { Background Ret inopathy in: } \\
\text { Proll ferat ive Ret Inopa thy }\end{array}$ \\
\hline
\end{tabular}

Fig. 5 Summary of the comparison of mean contrast thresholds. Differences significant at the level of at least $p=0.05$ are indicated by*.

categories of retinopathy. The test is, however, easily carried out and in conjunction with other findings may be useful in the assessment of the functional status of the eye in diabetic patients.

We thank Miss F. Maitland for secretarial assistance and Mr F. Addison for the preparation of the illustrations.

\section{References}

1 Kinnear PR, Aspinall PA, Lakowski R. The diabetic eye and colour vision. Trans Ophthalmol Soc UK 1972; 92: 69-78.

\begin{tabular}{|c|c|c|c|c|c|c|c|}
\hline Plate & 2 & 3 & 4 & $\mathbf{s}$ & B & 7 & Comparieon \\
\hline & & & & & & * & $\begin{array}{l}\text { Normal Controls v. } \\
\text { Arden Normals }\end{array}$ \\
\hline & * & * & * & * & * & * & $\begin{array}{l}\text { Arden Noran 1s v. } \\
\text { All Diabet tes }\end{array}$ \\
\hline & * & $*$ & \# & * & * & * & $\begin{array}{l}\text { Arden Norma 1s v. } \\
\text { No Retincopa thy }\end{array}$ \\
\hline & * & & * & $*$ & * & * & $\begin{array}{l}\text { Arden Noras 1s } 1 \text { v. } \\
\text { Beckground Ret inopa thy }\end{array}$ \\
\hline & * & \# & * & * & * & * & $\begin{array}{l}\text { Arden Noraale v. } \\
\text { Proll ferative Ret inopathy }\end{array}$ \\
\hline & $*$ & * & * & \# & * & * & $\begin{array}{l}\text { Noraal Controle v. } \\
\text { All Diebetice }\end{array}$ \\
\hline & * & * & * & * & $*$ & * & $\begin{array}{l}\text { Noraal Controls v. } \\
\text { No Ret Inopathy }\end{array}$ \\
\hline & & & * & * & * & * & $\begin{array}{l}\text { Normal Controle v. } \\
\text { Backeround Ret inopathy }\end{array}$ \\
\hline & * & * & 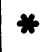 & $*$ & * & $*$ & $\begin{array}{l}\text { Noranal Controls v. } \\
\text { Proll ferat ive Ret inopa thy }\end{array}$ \\
\hline & & & & & * & * & $\begin{array}{l}\text { No Ret Inopat thy V. } \\
\text { Backeround Retinopathy }\end{array}$ \\
\hline & & * & & & & & $\begin{array}{l}\text { No Retinopathy v. } \\
\text { Proli ferat ive Ret inopathy }\end{array}$ \\
\hline & $*$ & * & & * & * & & $\begin{array}{l}\text { Background Ret inopa thy v. } \\
\text { Proll ferat ive Ret inopa thy }\end{array}$ \\
\hline
\end{tabular}

Fig. 6 Summary of the comparisons of the variances in contrast thresholds. Differences significant at the level of at least $p=0.05$ are indicated by*

2 Arden GB, Jacobson JJ. A simple grating test for contrast sensitivity: preliminary results indicate value in screening for glaucoma. Invest Ophthalmol Visual Sci 1978; 17: 23-32.

3 Singh H, Cooper RL, Alder VA, Crawford GJ, Terrell A, Constable IJ. The Arden grating acuity: effect of age and optical factors in the normal patient with prediction of the false negative in screening for glaucoma. Br J Ophthalmol 1981; 65: 518-24.

4 Skalka HW. Effect of age on Arden grating acuity. $\mathrm{Br} J$ Ophthalmol 1980; 64: 21-3. 